\title{
The effect of AMP on the NAD-dependent glutamate dehydrogenase during activation and morphogenesis in the cellular slime moulds
}

\author{
F. PAMUla* and J. F. WheldRAKe \\ School of Biological Sciences, The Flinders University of South Australia, GPO Box 2100, Adelaide 5001, Australia
}

(Received 23 January 1992; revised 12 May 1992; accepted 22 May 1992)

\begin{abstract}
In extracts from vegetative Dictyostelium discoideum V12 the basal NAD-dependent glutamate dehydrogenase (NAD-GDH) activity was low, but it increased on standing at $4{ }^{\circ} \mathrm{C}$. When $0 \cdot 1 \mathrm{mM}$-AMP was included in the assay mix, enzyme activity was stimulated nearly 30-fold. As the extract was allowed to age, the enzyme rapidly lost its ability to be stimulated by AMP. The response of NAD-GDH to AMP was also dependent on the stage of morphogenesis. The ratios of NAD-GDH activity assayed with and without AMP (+ AMP/-AMP ratios) in freshly prepared extracts from cells at $0,4,8$ and $12 \mathrm{~h}$ of development were similar, but declined later in morphogenesis. The + AMP/-AMP ratio decreased sharply during activation at $4^{\circ} \mathrm{C}$ in extracts from cells at 0 , 4,16 and $20 \mathrm{~h}$ of development. By contrast, extracts from cells starved for 8 and $12 \mathrm{~h}$ remained more responsive to AMP throughout activation. Analysis of Western blots showed that vegetative NAD-GDH did not undergo any detectable proteolytic cleavage during $96 \mathrm{~h}$ of activation at $4{ }^{\circ} \mathrm{C}$. Also, no change in molecular mass appeared to take place within the cells until culmination (20-24 h), when some breakdown products appeared. Activation of NAD-GDH also occurred in D. discoideum strains NC4 and AX3, and in D. mucoroides. In addition, the enzyme from these four strains was stimulated by AMP and the + AMP/-AMP ratio declined with similar kinetics during activation. The enzyme from Polysphondylium violaceum was not activated on standing, but it was stimulated by AMP. The effect of activation of NAD-GDH is discussed in relation to a postulated catabolic role for this enzyme.
\end{abstract}

\section{Introduction}

The cellular slime mould Dictyostelium discoideum is an ideal organism for studying the mechanisms of development because of the simplicity of its morphogenesis. D. discoideum is a free-living phagotrophic soil organism that feeds on bacteria and divides by binary fission. The cue to begin development in the asexual cycle is the depletion of its bacterial food source or amino acid starvation (Lee, 1972; Marin, 1976, 1977; Darmon \& Klein, 1978; Margolskee et al., 1980). Founder or initiator cells begin secreting cAMP in pulses (Sussman, 1956; Bonner, 1957; Ennis \& Sussman, 1958) to which the surrounding amoebae are attracted. The amoebae destroy the incoming signal as they move toward its source, and synthesize and secrete new cAMP; in this way the signal is propagated outward. About $10^{5}$

\footnotetext{
* Author for correspondence. Tel. (08) 2012032 ; fax (08) 2013015.
}

Abbreviations: ASMX-naphthol, 3-hydroxy-2-naphthoic acid-2,4dimethylanilide phosphate; NAD-GDH, NAD-dependent glutamate dehydrogenase. amoebae are entrained in this way to move in waves to the cAMP source (Alcantara \& Monk, 1974). As the amoebae continue to move into the aggregate, a tip emerges that subsequently acts as an organizing centre for the aggregate (Rubin \& Robertson, 1975). Amoebae continue moving towards the organizing centre and cause the formation of a bullet-shaped mass of cells called a slug. At this stage of morphogenesis, cells are pre-committed to either the spore or the stalk pathway. Pre-spore cells are located in the posterior and pre-stalk cells the anterior of the slug (MacWilliams \& Bonner, 1979). Under favourable conditions the slug undergoes a series of morphological changes resulting in the formation of a fruiting body composed of two main cell types, spore and stalk cells. The life cycle of $D$. discoideum, therefore, has two distinct phases, growth and morphogenesis. This property makes slime moulds an ideal system to study development because developmental processes are uncomplicated by concurrent cell division. There is, though, some evidence to suggest that the position of the amoebae in the cell cycle, at the onset of aggregation, may predispose a cell to either the stalk or 
the spore pathway (Maeda \& Maeda, 1974; Zada-Hames \& Ashworth, 1978; Sharpe \& Watts, 1985).

Several diffusible molecules play key roles in regulating differentiation; these include cAMP, differentiation-inducing factor (DIF), adenosine and ammonia (Williams, 1988). cAMP not only serves as the chemotactic signal but also promotes morphogenesis. Ammonia delays aggregation in aggregation-competent cells by reducing the level of intracellular cAMP (Thadani $e t$ al., 1977; Schindler \& Sussman, 1979) and thus inhibits terminal differentiation. In the aggregate, DIF and ammonia play antagonistic roles: DIF promotes stalk cell differentiation and inhibits spore cell differentiation while ammonia has the opposite effect (Williams, 1988). Ammonia, though, also works much earlier by inhibiting DIF accumulation (Neave et al., 1983). Thus the depletion of ammonia coupled with a rise in DIF may trigger stalk cell differentiation in intact slugs (Wang \& Schaap, 1989). In addition, ammonia has been shown to switch cells from the prestalk to the prespore pathway (Bradbury \& Gross, 1989) and is an inducer of differentiation at the protein and mRNA level (Oyama $e t$ al., 1988).

We have been examining the NAD-dependent glutamate dehydrogenase (NAD-GDH), an enzyme of central importance in amino acid metabolism, in D. discoideum. Glutamate dehydrogenase catalyses the interconversion of glutamate to 2-oxoglutarate, a key TCA cycle intermediary, and ammonia. NAD-GDH is important because it is one of the few enzymes that can catalyse the incorporation of ammonia to form amino acids and is therefore a candidate for control of the level of ammonia, which is a key morphogen in $D$. discoideum. We have shown that the NAD-GDH from $D$. discoideum is activated up to 10 -fold on standing at $4{ }^{\circ} \mathrm{C}$ (Pamula \& Wheldrake, 1990) and that the purified enzyme is stimulated by AMP (Pamula \& Wheldrake, 1991). Although enzyme activity increases on the addition of AMP, the $K_{\mathrm{m}}$ for its substrates also increases. We show here that activation is not unique to the enzyme from $D$. discoideum and that the response of the enzyme to AMP varies during development.

\section{Methods}

Materials. 2-Oxoglutarate, NADH and AMP were from Boehringer, pre-stained markers and Fast Red were from Bio-Rad, ASMXNaphthol and chloramphenicol were from Sigma, Immobilon-P was from Millipore, and Freund's adjuvant was from Difco. All other reagents used were of the highest grade available.

Preparing cell extracts. Polysphondylium violaceum strain Tokyo, Dictyostelium mucoroides strain Chicago and Dictyostelium discoideum strains V12 and NC4 were grown in liquid co-culture with Enterobacter aerogenes as described previously (Pamula \& Wheldrake, 1988).
Dictyostelium discoideum strain AX3 was grown in HL5 medium (Sussman, 1987). Amoebae were harvested at $3-5 \times 10^{6}$ cells $\mathrm{ml}^{-1}$ by centrifugation $\left(200 \mathrm{~g}\right.$ for $10 \mathrm{~min}$ at $\left.4^{\circ} \mathrm{C}\right)$ then washed three times by resuspending the cell pellet in KK2 (Pamula \& Wheldrake, 1988) and centrifugation as outlined above. Cells were used immediately, or stored at $-20^{\circ} \mathrm{C}$ until required. All experiments were performed at least twice.

To obtain $D$. discoideum $\mathrm{V} 12$ at various stages of morphogenesis, amoebae were grown in liquid co-culture to $3 \times 10^{6}$ cells ml $^{-1}$. Cultures were harvested by centrifugation, then washed three times in KK2 as before. The washed amoebae were deposited on KK2 agar $(1.5 \%$, w/v) at $5 \times 10^{6}$ cells cm$^{-2}$ and allowed to develop under lights at $22^{\circ} \mathrm{C}$. When required, cells at different stages of differentiation were gently scraped off the agar, washed in KK2 and stored at $-20^{\circ} \mathrm{C}$.

Cell pellets were resuspended in 7.5 volumes of sonication buffer $0.1 \%$ Triton X-100 in $25 \mathrm{mM}$-Tris $/ \mathrm{HCl}, \mathrm{pH} 8.0)$ and sonicated $(2 \times 10 \mathrm{~s})$ with a Sony sonicator probe at maximum setting. The crude extract was then centrifuged for $10 \mathrm{~min}$ at $4{ }^{\circ} \mathrm{C}$ in an Eppendorf bench centrifuge and the supernatant retained for assaying. When required, chloramphenicol was used at $0.25 \mathrm{mg} \mathrm{ml}^{-1}$.

Assays. NAD-GDH was assayed by measuring the oxidation of NADH at $340 \mathrm{~nm}$ using a Hitachi recording spectrophotometer (Pamula \& Wheldrake, 1991). When measuring the effect of AMP on NAD-GDH activity, AMP was used at a final concentration of $0.1 \mathrm{~mm}$. Protein was assayed by the method of Bradford (1976) using bovine serum albumin to construct the standard curve.

Antibody production. Antibodies were raised in a 6 month old New Zealand White rabbit essentially as described by Livingston (1973). Briefly, purified NAD-GDH $(50 \mu \mathrm{g})$ was dissolved in $1 \mathrm{ml}$ phosphatebuffered saline (PBS) to which $1 \mathrm{ml}$ of complete Freund's adjuvant was added. This was thoroughly mixed then injected intradermally at several sites along the animal's back. Two further injections were given: one 2 weeks and the other 7 weeks after the initial injection. In both injections $15 \mu \mathrm{g}$ of pure protein was used as outlined above but using Freund's incomplete adjuvant. Three weeks after the last injection, blood was collected then allowed to clot at $37^{\circ} \mathrm{C}$ for $30 \mathrm{~min}$. The clot retracted after overnight incubation at $4{ }^{\circ} \mathrm{C}$ and the serum was collected by centrifugation $\left(3000 \mathrm{~g}\right.$ for $10 \mathrm{~min}$ at $4{ }^{\circ} \mathrm{C}$ ) and stored at $-80^{\circ} \mathrm{C}$.

Western blotting and staining. Crude extracts were separated on SDSpolyacrylamide $(12 \%, w / v)$ gels (Laemmli, 1970). Proteins were then transferred onto Immobilon using the Bio-Rad Mini-Trans Blot apparatus according to the manufacturer's instructions. Membranes were blocked for $1 \mathrm{~h}$ with $0.5 \%$ Tween 20 in PBS at room temperature. The blocked membranes were then incubated with serum and $0.1 \%$ Tween 20 in PBS overnight at $4{ }^{\circ} \mathrm{C}$. Blots were rinsed briefly with $0.1 \%$ Tween 20 in PBS and incubated for $\mathrm{I} h$ at room temperature with antirabbit antibody conjugated to alkaline phosphatase. After rinsing with $0.1 \%$ Tween 20 in PBS, the blots were incubated in alkaline phosphatase substrate (0.5 mg ASMX-naphthol ml-1, $1 \mathrm{mg}$ Fast Red $\mathrm{ml}^{-1}, 5 \mathrm{~mm}-\mathrm{MgCl}_{2}$ in $100 \mathrm{~mm}$-Tris/HCl, pH 9.0). When the bands were well developed the reaction was stopped by soaking the blots in distilled water. Each Western blot was repeated three times to confirm the reproducibility of the results.

\section{Results}

Chloramphenicol and activation

We have shown previously (Pamula \& Wheldrake, 1990) that NAD-GDH from $D$. discoideum is activated in crude 


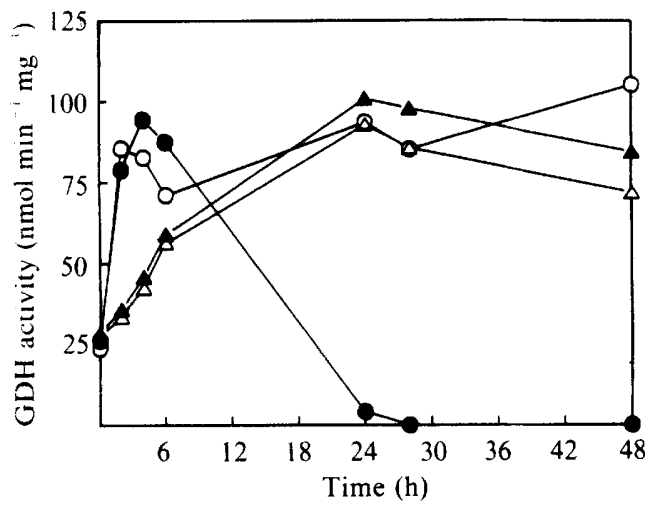

Fig. 1. Time-dependent activation of NAD-GDH in extracts from vegetative $D$. discoideum $\mathrm{V} 12$ at $4{ }^{\circ} \mathrm{C}$ with $(\triangle)$ and without $(\Delta)$ chloramphenicol, and at $27^{\circ} \mathrm{C}$ with $(\mathrm{O})$ and without $(\bullet)$ chloramphenicol. Assays were performed as described in Methods in the absence of AMP. Each data point represents the mean of duplicate determinations.

extracts on standing at $4{ }^{\circ} \mathrm{C}$. Activation of NAD-GDH is usually monitored over $48 \mathrm{~h}$, and it was thus important to determine if the increase in enzyme activity was due to bacterial contamination, although we have been unable to detect any NAD-GDH activity in $E$. aerogenes (unpublished results), a major contaminant of slime moulds grown in co-culture. To examine this question further, chloramphenicol was included in the crude extracts and NAD-GDH activity was monitored over $48 \mathrm{~h}$ (Fig. 1). The presence of chloramphenicol had no effect on activation of NAD-GDH at $4{ }^{\circ} \mathrm{C}$. At $27^{\circ} \mathrm{C}$, activation of NAD-GDH occurred more quickly than at $4{ }^{\circ} \mathrm{C}$, but if chloramphenicol was not included no NADGDH activity was detectable after $30 \mathrm{~h}$.

\section{AMP stimulation during activation}

The activity of purified NAD-GDH from pre-incubated extracts is stimulated by AMP (Pamula \& Wheldrake, 1991). AMP does not affect the kinetics of activation (unpublished results), suggesting that AMP may be an important allosteric modulator of this enzyme. It was therefore important to examine if the level of stimulation of NAD-GDH by AMP was the same throughout the period of activation. When activation of NAD-GDH was followed in crude extracts from vegetative cells at $4{ }^{\circ} \mathrm{C}$ the characteristic increase in enzyme activity was observed (Fig. 2). Enzyme activity in the presence of $0.1 \mathrm{mM}$-AMP was high initially but then decreased. The ratio of activity with and without AMP (+ AMP/ - AMP ratio) decreased rapidly during the activation period (Fig. 2).

Since all the work on the properties of the NAD-GDH

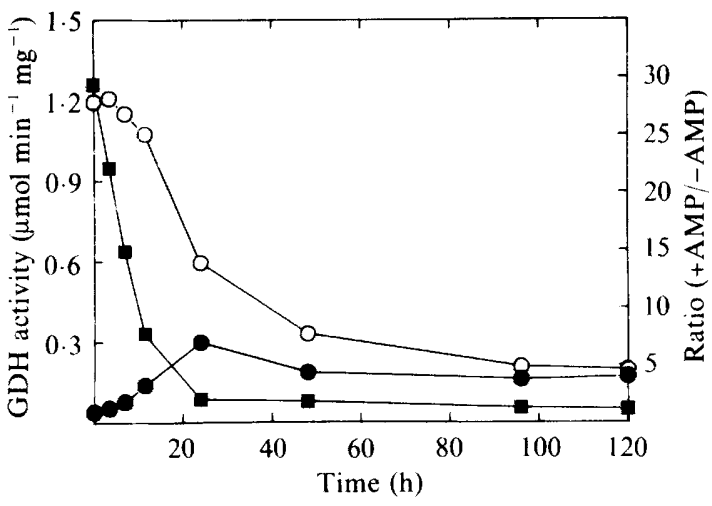

Fig. 2. Time-dependent activation of NAD-GDH in extracts from vegetative $D$. discoideum $\mathrm{V} 12$ at $4{ }^{\circ} \mathrm{C}$. Glutamate dehydrogenase activity was assayed with $(O)$ or without (O) $0.1 \mathrm{mM}$-AMP. The + AMP/-AMP ratio is also shown ( $\boldsymbol{\square})$. The experiment was performed three times with similar results. Representative results are shown.

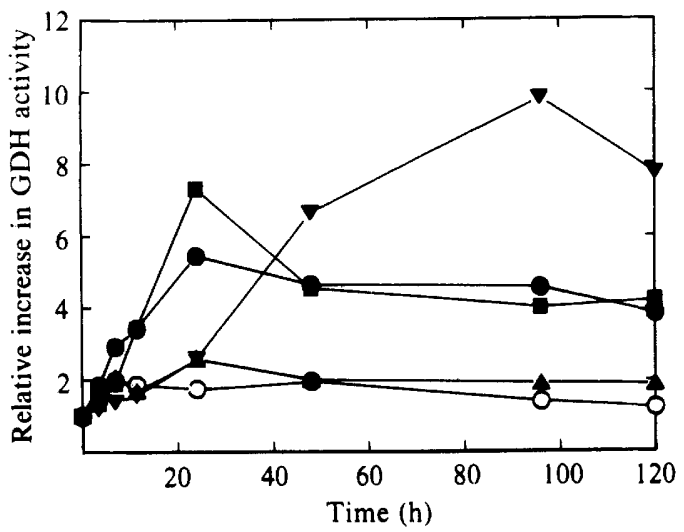

Fig. 3. Increase of NAD-GDH activity at $4{ }^{\circ} \mathrm{C}$ in extracts from vegetative cells of various slime mould strains: $D$. discoideum $\mathrm{V} 12(\boldsymbol{\square})$, $\mathrm{NC} 4(\nabla)$ and AX3 $(\bullet), D$. mucoroides $(\Delta)$ and $P$. violaceum $(O)$. Activity is given relative to that at $0 \mathrm{~h}$. Initial specific activities for D. discoideum $\mathrm{VI} 2, \mathrm{NC4}, \mathrm{AX} 3, D$. mucoroides and $P$. violaceum were 41 , $36,55,69$ and $11 \mathrm{nmol} \mathrm{min}{ }^{-1} \mathrm{mg}^{-1}$ respectively. The experiment was performed at least twice with similar results. Representative results are shown.

enzyme had hitherto been performed on $D$. discoideum V12, it was decided to determine if other strains and species of slime mould have a NAD-GDH enzyme that can be activated on standing and whether it also is stimulated by AMP. The NAD-GDH enzymes in $D$. discoideum $\mathrm{V} 12, \mathrm{NC} 4$ and $\mathrm{AX} 3$ and $D$. mucoroides were all activated during incubation at $4{ }^{\circ} \mathrm{C}$ (Fig. 3) but the rates of activation varied. NAD-GDH from strain V12 showed a more rapid increase than NC4 or AX3, while the rate and extent of activation of the D. mucoroides enzyme were limited. The NAD-GDHs 


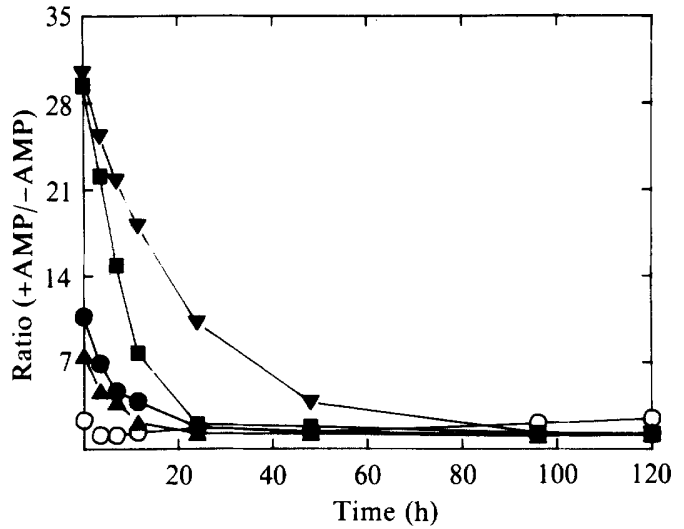

Fig. 4. The + AMP/-AMP ratio for NAD-GDH in extracts from vegatative cells of various slime mould strains: D. discoideum V12 (D), $\mathrm{NC4}(\boldsymbol{\nabla})$ and $\mathrm{AX} 3(\bullet)$, D. mucoroides $(\boldsymbol{\Delta})$ and $P$. violaceum $(O)$. Assays were carried out in the absence and in the presence of $0.1 \mathrm{mM}$-AMP, on extracts incubated at $4^{\circ} \mathrm{C}$. The experiment was performed at least twice with similar results. Representative results are shown.

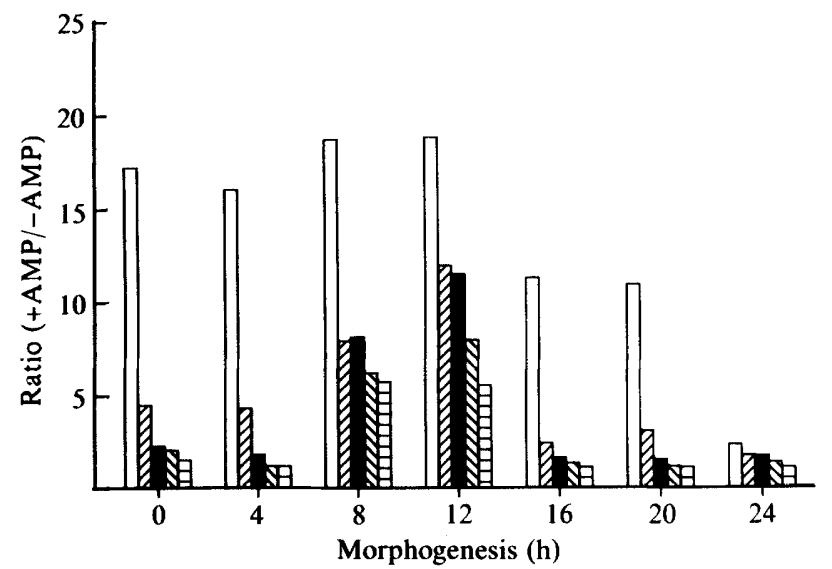

Fig. 5. The + AMP/-AMP ratio in D. discoideum V12 during activation at various stages of development. The + AMP/-AMP ratio was determined after $0(\square), 24(\mathbb{Z}), 48(\square), 72(\mathbb{\$})$ and $96 \mathrm{~h}$ (目) of activation at $4{ }^{\circ} \mathrm{C}$. Assays were carried out in the absence and in the presence of $0.1 \mathrm{mM}$-AMP. Each data point represents the mean of duplicate assays.

from these four strains were stimulated by AMP and the decline in AMP stimulation during activation followed a similar time course (Fig. 4). As with activation, the rate of loss of AMP stimulation was more rapid for V12 than for NC4, with the D. mucoroides enzymes showing less initial AMP stimulation. $P$. violaceum had very low levels of NAD-GDH activity and the enzyme did not appear to be activated on standing. However, NAD-GDH activity in $P$. violaceum extracts was stimulated slightly by AMP.

In $D$. discoideum V12 the response of the NAD-GDH enzyme to AMP was dependent on the stage of

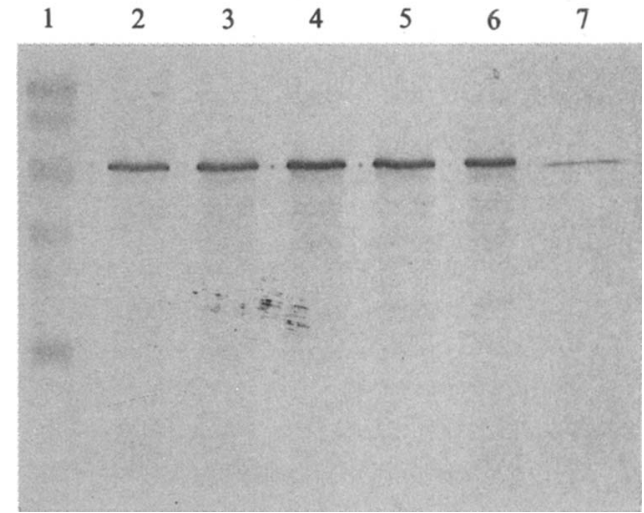

Fig. 6. Immunoblot, using anti-NAD-GDH antiserum, of extracts of vegetative $D$. discoideum V12 sampled at various times during activation at $4{ }^{\circ} \mathrm{C}$. Lane 1 , marker proteins (phosphorylase $b, 110 \mathrm{kDa}$; bovine serum albumin, $84 \mathrm{kDa}$; ovalbumin, $47 \mathrm{kDa}$; carbonic anhydrase, $33 \mathrm{kDa}$; soybean trypsin inhibitor, $24 \mathrm{kDa}$; and lysozyme, $16 \mathrm{kDa}$ ); lanes 2-6, activation for $0 \mathrm{~h}$ (lane 2), $24 \mathrm{~h}$ (lane 3), $48 \mathrm{~h}$ (lane 4), $72 \mathrm{~h}$ (lane 5) and $96 \mathrm{~h}$ (lane 6); lane 7, NAD-GDH purified from D. discoideum $\mathrm{V} 12$.

development. The stimulation by AMP in freshly prepared extracts was similar for NAD-GDH from cells at 0 (vegetative), 4 (early aggregation), 8 (aggregation) and $12 \mathrm{~h}$ (slug), but declined at later times, with extract from $20 \mathrm{~h}$ (culmination) showing a much reduced effect (Fig. 5). Activation is usually accompanied by a loss of AMP stimulation, but extracts from cells at 8 and $12 \mathrm{~h}$ remained more responsive to AMP throughout the activation period (Fig. 5).

\section{Stability of NAD-GDH in crude extracts}

One possible mechanism of activation of NAD-GDH could be proteolytic attack. Proteolysis of NAD-GDH could cause both activation and the loss of stimulation by AMP. To test this possibility, samples from vegetative cell extracts taken at various times during activation were separated by SDS-polyacrylamide gel electrophoresis, then transferred to Immobilon and probed with polyclonal antibodies raised against purified NADGDH. Fig. 6 shows that NAD-GDH did not appear to undergo any significant proteolytic cleavage during $96 \mathrm{~h}$ incubation at $4{ }^{\circ} \mathrm{C}$ (compares lanes 2 to 6 ).

Proteolysis was also a possible cause of the change in NAD-GDH activity observed during development. However, Western blot analysis revealed that no change in molecular mass appeared to take place until cells had starved for 20-24 h (Fig. 7a), when some breakdown products appeared. No additional breakdown of NADGDH appeared to occur between 0 and $96 \mathrm{~h}$ of activation in samples from any of the phases of development 

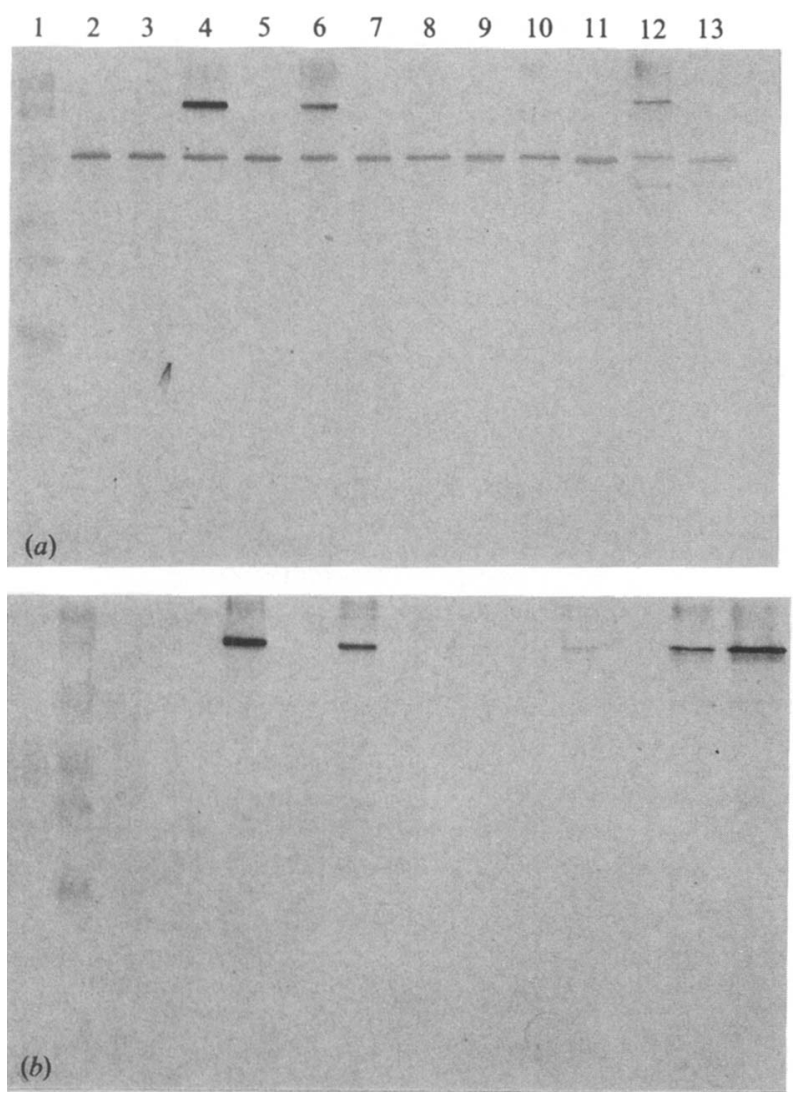

Fig. 7. Immunoblot of extracts of $D$. discoideum $\mathrm{V} 12$ taken at various times during development. (a) Blot with anti-NAD-GDH antiserum; (b) blot with pre-immune serum. Lane 1, marker proteins (see Fig. 6); lanes $2-3,4-5,6-7,8-9,10-11$ and $12-13$ are samples taken after starvation for $0 \mathrm{~h}$ (vegetative), $4 \mathrm{~h}$ (early aggregation), $8 \mathrm{~h}$ (aggregation), $16 \mathrm{~h}$ (early culmination), $20 \mathrm{~h}$ (culmination) and $24 \mathrm{~h}$ (mature fruiting body). Even-numbered tracks are samples taken within $30 \mathrm{~min}$ of cell breakage and odd-numbered tracks are samples after $96 \mathrm{~h}$ activation at $4^{\circ} \mathrm{C}$.

examined. A high-molecular-mass band was recognized by the antibodies (lanes 4, 6 and 12) that disappeared on activation; however, this band was also present in preimmune controls (Fig. $7 b$ ).

\section{Discussion}

Since $D$. discodeum V12 is grown using Enterobacter aerogenes as a food source and because activation of NAD-GDH is examined in crude extracts over a long period of time, it was possible that activation could be due to bacterial contamination. Although it was reported by Smith et al. (1975), and confirmed by us, that $E$. aerogenes does not contain a NAD-GDH, it was still necessary to verify that activation was not due to bacterial contamination. This was done by including chloramphenicol in the crude extracts and measuring activity over time. Chloramphenicol did not inhibit activation of NAD-GDH (Fig. 1) but if it was not included when incubating at $27^{\circ} \mathrm{C}$ no NAD-GDH activity could be detected after $30 \mathrm{~h}$. Therefore, activation of NAD-GDH is not due to bacterial contamination, although the loss of activity at $27^{\circ} \mathrm{C}$ without chloramphenicol can be explained in this way. That activation of NAD-GDH at $4{ }^{\circ} \mathrm{C}$ is not of bacterial origin is supported by the observation that $D$. discoideum AX3 grown in axenic culture has a NAD-GDH enzyme that is activated on standing at $4{ }^{\circ} \mathrm{C}$ (Fig. 3).

Previous studies, based on ion-exchange and gelfiltration chromatography (Pamula \& Wheldrake, 1990), indicated that activation of NAD-GDH was probably not due to proteolytic cleavage. The experiments reported here using antibodies (Figs 6 and 7) do not totally eliminate the possibility that proteolysis is the mechanism of activation. However, since no change in molecular mass of NAD-GDH was dectected over the $96 \mathrm{~h}$ period of activation used in these experiments, any such cleavage can only be very limited in extent.

AMP has two important effects on NAD-GDH: it increases both $V_{\max }$ and the $K_{\mathrm{m}}$ for 2-oxoglutarate and NADH (Pamula \& Wheldrake, 1991). Given that a high AMP concentration indicates a low energy status in the cell, and that the properties of NAD-GDH vary throughout development, with GDH from early differentiation being the most responsive to AMP (Fig. 4), then these observations are compatible with a catabolic role for NAD-GDH in vegetative cells. In the vegetative stage nutrients are freely available so amino acids will be available for catabolism in response to a decrease in energy charge. Under these conditions a rise in AMP would immediately stimulate NAD-GDH activity. Late in morphogenesis, when nutrient levels are lower and the basal level of AMP would probably be higher, a decrease in response of NAD-GDH to AMP would be expected. Further, spore cells accumulate large amounts of both glutamate (Wright \& Bard, 1963) and glutamine (Klein et al., 1990) and the observed decrease in the NAD-GDH activity is presumably necessary if glutamate levels are to remain high.

The concentration of AMP in D. discoideum has not been determined, but if it is similar to that found in Escherichia coli (Lowry et al., 1971) or Saccharomyces cerevisiae (Gancedo \& Gancedo, 1973), 150 and 170$300 \mu \mathrm{M}$ respectively, then the regulatory effect of AMP on the NAD-GDH enzyme is potentially very important. The importance of AMP as a regulator of NAD-GDH is reinforced by the fact that the enzyme from all strains examined is stimulated by AMP. 


\section{References}

Alcantara, F. \& Monk, M. (1974). Signal propagation during aggregation in the slime mould Dictyostelium discoideum. Journal of General Microbiology 85, 321-334.

BONNER, J. T. (1957). A theory of the control of differentiation in the cellular slime molds. Quarterly Review of Biology 32, 232-246.

BradBuRy, J. M. \& Gross, J. D. (1989). The effect of ammonia on celltype-specific enzyme accumulation in Dictyostelium discoideum. Cell Differentiation and Development 27, 121-128.

BRADFORD, M. M. (1976). A rapid and sensitive method for the quantitation of microgram quantities of protein utilizing the principle of protein-dye binding. Analytical Biochemistry 72, $248-254$

Darmon, M. \& Klein, C. (1978). Effects of amino acids and glucose on adenylate cyclase and cell differentiation of Dictyostelium discoideum. Developmental Biology 63, 377-389.

ENNIs, H. L. \& Sussman, M. (1958). The initiator cell for slime mold aggregation. Proceedings of the National Academy of Sciences of the United States of America 44, 401-411.

GANCEDO, J. M. \& GANCEDO, C. (1973). Concentrations of intermediary metabolites in yeast. Biochimie 55, 205-211.

Klein, G., Cotter, D. A., Martin, J.-B. \& SATre, M. (1990). A natural-abundance ${ }^{13} \mathrm{C}$-NMR study of Dictyostelium discoideum metabolism. Monitoring of the spore germination process. European Journal of Biochemistry 93, 135-142.

LAEMmLi, U. K. (1970). Cleavage of structural proteins during the assembly of the head of bacteriophage T4. Nature, London 227 , 680-685.

LeE, K. C. (1972). Permeability of Dictyostelium discoideum towards amino acids and inulin: a possible relationship between initiation of differentiation and loss of 'pool' metabolites. Journal of General Microbiology 72, 457-471.

Livingston, D. M. (1973). Immunoaffinity chromatography of proteins. Methods in Enzymology 34, 723-731.

LONG, B. H. \& CoE, E. L. (1974). Changes in neutral lipid constituents during differentiation of the cellular slime mold, Dictyostelium discoideum. Journal of Biological Chemistry 249, 521-529.

Lowry, O. H., Carter, J., Ward, J. B. \& Glaser, L. (1971). The effect of carbon and nitrogen sources on the level of metabolic intermediates in Escherichia coli. Journal of Biological Chemistry 246, 6511-6521.

MaCWilliams, H. K. \& BonNer, J. T. (1979). The prestalk-prespore pattern in cellular slime molds. Differentiation 14, $1-22$.

MAEDA, Y. \& MAEDA, M. (1974). Heterogeneity of the cell population of the cellular slime mold Dictyostelium discoideum before aggregation, and its relation to the subsequent location of the cells. Experimental Cell Research 84, 88-94.

Margolskee, J. P., Froshauer, S., Skrinska, R. \& Lodish, H. F. (1980). The effects of cell density and starvation on early developmental events in Dictyostelium discoideum. Developmental Biology 74, 409-421.

MaRIN, F. T. (1976). Regulation of development in Dictyostelium discoideum. I. Initiation of the growth to development transition by amino acid starvation. Developmental Biology 48, 110-117.

Marin, F. T. (1977). Regulation of development in Dictyostelium discoideum. II. Regulation of early cell differentiation by amino acid starvation and intercellular interaction. Developmental Biology 60, 389-395.

MURPHY, M. \& KLEIN, C. (1979). Effects of amino acids on cell differentiation of $D$. discoideum. Cell Differentiation 8, 275-284.

NeAVE, N., Sobolewski, A. \& WeEks, G. (1983). The effect of ammonia on stalk cell formation in submerged monolayers of Dictyostelium discoideum. Cell Differentiation 13, 301-307.

Oyama, M., Kubohara, Y., Oohata, A. A. \& OKamoto, K. (1988) Role of cyclic AMP and ammonia in induction and maintenance of post-aggregative differentiation in a suspension culture of Dictyostelium discoideum. Differentiation 38, 11-16.

Pamula, F. \& WheldRAKE, J. F. (1988). Properties and developmental regulation of the protein phosphatases in Dictyostelium discoideum. Biochemistry International 17, 535-543.

Pamula, F. \& Wheldrake, J. F. (1990). Activation of the NADHdependent glutamate dehydrogenase during morphogenesis of Dictyostelium discoideum. Biochemistry International 20, 623-631.

Pamula, F. \& Wheldrake, J. F. (1991). The NAD-dependent glutamate dehydrogenase from Dictyostelium discoideum: purification and properties. Archives of Biochemistry and Biophysics 291, 255-230.

Rubin, J. \& Robertson, A. (1975). The tip of the Dictyostelium discoideum pseudoplasmodium as an organizer. Journal of Embryology and Experimental Morphology 33, 227-241.

SCHINDLER, J. \& SUSSMAN, M. (1979). Inhibition by ammonia of intracellular cAMP accumulation in Dictyostelium discoideum: its significance for the regulation of morphogenesis. Developmental Genetics 1, 13-20.

Sharpe, P. T. \& WatTS, D. J. (1985). The role of the cell cycle in differentiation of the cellular slime mould Dictyostelium discoideum. Molecular and Cellular Biochemistry 67, 3-9.

Smith, E. L., Austen, B. M., Blumenthal, K. M. \& NyC, J. F. (1975). Glutamate dehydrogenases. In The Enzymes, pp. 293-367. Edited by P. D. Boyer. New York: Academic Press.

Sussman, M. (1956). On the relation between growth and morphogenesis in the slime mold Dictyostelium discoideum. Biological Bulletin 110, 91-95.

Sussman, M. (1987). Cultivation and synchronous morphogenesis of Dictyostelium under controlled experimental conditions. Methods in Cell Biology 28, 9-29.

Thadani, V., Pan, P. \& Bonner, J. T. (1977). Complementary effects of ammonia and cAMP on aggregation territory size in the cellular slime mold Dictyostelium mucoroides. Experimental Cell Research 108, 75-78.

WANG, M. \& SchaAP, P. (1989). Ammonia depletion and DIF trigger stalk cell differentiation in intact Dictyostelium discoideum slugs. Development 105, 569-574.

Williams, J. G. (1988). The role of diffusible molecules in regulating the cellular differentiation of Dictyostelium discoideum. Development 103, 1-16.

WrIGHT, B. E. \& BARD, S. (1963). Glutamate oxidation in the differentiating slime mold. I. Studies in vivo. Biochimica et Biophysica Acta 53, 45-49.

ZaDa-Hames, I. M. \& Ashworth, J. M. (1978). The cell cycle and its relationship to development in Dictyostelium discoideum. Developmental Biology 63, 307-320. 